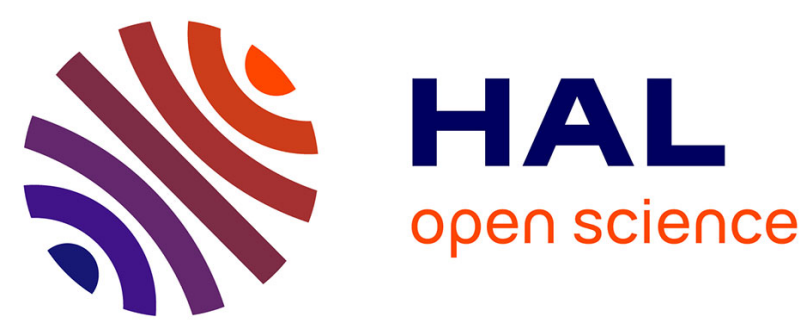

\title{
Effects of Active Muscle Forces on Driver's Lower Limb Injuries due to Emergency Brake in Various Frontal Impacts
}

Fan Li, Wei Huang, Xingsheng Wang, Xiaojiang Lv, Fuhao Mo

\section{- To cite this version:}

Fan Li, Wei Huang, Xingsheng Wang, Xiaojiang Lv, Fuhao Mo. Effects of Active Muscle Forces on Driver's Lower Limb Injuries due to Emergency Brake in Various Frontal Impacts. Proceedings of the Institution of Mechanical Engineers, Part D: Journal of Automobile Engineering, 2020, 234 (7), pp.2014-2024. 10.1177/0954407019870704 . hal-03230520

\section{HAL Id: hal-03230520 \\ https://hal-amu.archives-ouvertes.fr/hal-03230520}

Submitted on 20 May 2021

HAL is a multi-disciplinary open access archive for the deposit and dissemination of scientific research documents, whether they are published or not. The documents may come from teaching and research institutions in France or abroad, or from public or private research centers.
L'archive ouverte pluridisciplinaire HAL, est destinée au dépôt et à la diffusion de documents scientifiques de niveau recherche, publiés ou non, émanant des établissements d'enseignement et de recherche français ou étrangers, des laboratoires publics ou privés. 


\title{
Effects of Active Muscle Forces on Driver's Lower Limb Injuries due to Emergency Brake in Various Frontal Impacts
}

\author{
Fan $\mathrm{LI}^{1}$, Wei Huang ${ }^{1}$, Xingsheng $\mathrm{WANG}^{1}$, Xiaojiang Lv ${ }^{1,3}$, Fuhao MO ${ }^{1,2^{*}}$ \\ ${ }^{1}$ State Key Laboratory of Advanced Design and Manufacture for Vehicle Body, Hunan \\ University, Changsha, Hunan 410082, China \\ ${ }^{2}$ Aix-Marseille University, IFSTTAR, LBA UMRT24, Marseille, France \\ ${ }^{3}$ Zhejiang Key Laboratory of Automobile Safety Technology, GEELY Automobile Research \\ Institute, Hangzhou 311228, China \\ *Corresponding Author Email: fuhaomo@hnu.edu.cn
}

\begin{abstract}
Accident data shows that driver's kinematics response in real accidents can be significantly different from that in dummy or cadaver tests because of driver's muscle contraction. In this study, a finite element (FE) human body model consisting of an upper body of a dummy model and a lower limb-pelvis biomechanical model with 3D active muscles was developed to in-depth investigate lower limb injuries. Driver's emergency reaction during frontal impact was simulated by modelling muscle active contraction based on a series of volunteer experimental tests. Besides, a realistic impact environment with the response of the restraint system and the invasion of the driver's compartment was established in this study. The results show that muscle contraction can cause extra loads on lower limbs during the impact, which can increase the injury risk of lower limbs. As for the femur injury, muscle contraction caused an additional $1 \mathrm{kN}$ axial load on the femur and the femur resultant bending moment of active models was also higher by about 10-40Nm. Besides, the tibial index of the model with muscle activation was about 0.1 higher. Additionally, the results indicate that the femur injury is strongly related to the combined action of both axial force and bending moment. And the variation of the injury tolerance along the tibia shaft should be considered when evaluating the tibia injury. Overall, the current lower limb injury criteria can be still lack of robustness.
\end{abstract}

Keywords: Lower limb; Muscle contraction; Frontal impact; Injury criteria; Finite element 


\section{Introduction}

With a wide use of restraint systems in cars, fatal injuries of head and chest have been greatly limited [1]. However, lower limb injury prevalence has not been reduced [2]. Previous biomechanical cadaver tests showed that most Knee-Thigh-Hip (KTH) injuries of lower limbs occurred in distal femur and patella [3-5]. However, Rupp et al. [6] analysed the statistics of Japan traffic accident data and concluded that the pelvis joint injury accounted for $42 \%$ of the lower extremity injury in frontal crashes followed by the femur fracture accounting for $32 \%$. Other studies also showed similar results [7, 8]. To explain such difference, some studies indicated that previous biomechanical tests didn't properly consider the combined effects of femur axial forces and bending moments [9-12]. Some believed that muscle active contraction during drivers' emergency braking action plays an important role [13-16].

Ejima et al. [17] drew a conclusion from Institute for Traffic Accident Research and Data Analysis (ITARDA) that more than $60 \%$ of car drivers in Japan made evasive manoeuvres on braking with their feet when they realized an unavoidable accident. In these emergency cases, they might prepare their bodies by bracing muscles in order to face the upcoming impacts. All these actions can change their kinematic responses during the crash due to the active muscular forces as well as the muscular stiffness. Therefore, occupant behaviours in real accidents can be significantly different from the responses obtained in dummy or cadaver tests.

Since no muscle active contractraction can be involved in the cadaver tests, it's an effective method to investigate active muscle effects in frontal crashes by using biomechanical human body models with muscle contraction modelled. Silvestri [18] developed a lower limb skeletal model for the study of lower limb injury mechanism based on the work of Schauer [19]. This model used 1D spring elements and *MAT_SPRING_MUSCLE material in Ls-dyna to simulate muscles. Chang [15] estimated the activation levels of muscle groups by what is called equivalence principle based on electromyogram (EMG) signals. And the activation 
levels were then loaded into a lower limb FE model containing a 35-bundle 1D active muscle unit. However, muscles in his model were modelled with only $1 \mathrm{D}$ elements, the material parameters were antiquated, and the equivalence method to get the muscle activation levels needed to be verified.

With the development of modelling method, muscle models with higher fidelity gradually emerged. Chang et al. $[14,15]$ developed a FE model of a midsize male's pelvis and his lower extremities with 35 Hill-type muscles in each extremity. He found that muscle activation increases the bending moment in the femoral shaft, thereby increasing the risk of femoral shaft fractures by $20 \%-40 \%$. Both Behr [20] and Iwamoto [21] conducted volunteer emergency braking experiments and measured the surface EMG signal to obtain muscle activation levels, which were then used to simulate the lower limb muscle activity in fontal collisions. Generally, all of these models mentioned above used simplified loading conditions. The effect of the restraint system and the invasion of the driver's compartment were not taken into account. The specific injury criteria such as the femur axial force, the femur bending moment, or the tibial index were not given. And different frontal crash conditions were not considered.

Therefore, the present study aims to investigate the role of active muscles in the injury of occupant lower extremities during realistic frontal crashes. A lower limb-pelvis FE model with detailed 3D muscles was used in this study. Muscles' active levels during the emergency braking were obtained by volunteer emergency braking tests. Its biofidelity of both passive and active properties has been validated against recent experimental tests [16]. A realistic frontal crash model for simulating real accidents was then established. Both the response of a detailed restraint system and the invasion of the driver's compartment were taken into account in this paper. Different kinds of frontal impacts with different overlap rates were simulated to investigate the effects of muscle active contraction during the emergency braking on lower limb injury occurrences. 


\section{Methods}

\subsection{Lower limb-pelvis FE model with active 3D muscles}

A lower limb-pelvis model with active 3D muscles was used in this study to investigate the effect of muscle active contraction on lower limb injuries during emergency braking. The model geometry was extracted by software Geomagic and Mimics from the computed tomography (CT) scans of bones and Magnetic resonance imaging (MRI) scans of soft tissue. The FE model was developed in LS-DYNA codes by HyperMesh. Considering the influence of element size on computational accuracy and efficiency, most of element sizes were controlled between 4 and $8 \mathrm{~mm}$. As shown in Fig. 1, each muscle of the lower limb-pelvis model consists of three parts: tendon units modelled by non-linear spring elements, muscle passive property modelled by hexagonal elements and muscle active contraction modelled by 1D elements. Muscle passive property was modelled by the Ogden constitutive model in Lsdyna.

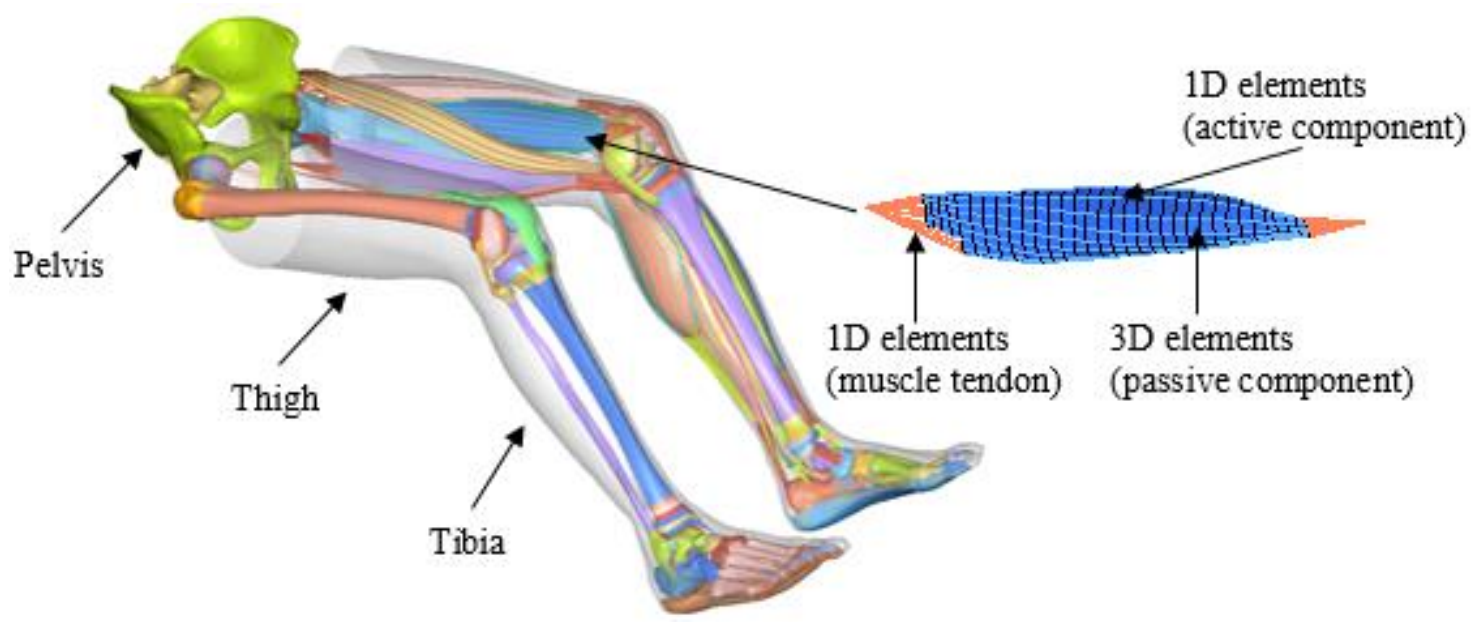

Figure 1. A lower limb-pelvis FE model with 3D active muscles

Muscle active contraction was modelled by the Hill constitutive model in Ls-dyna. The muscle active contraction force is defined as follows.

$$
F_{c e}=A(t) F_{l}(l) F_{V}(V) F_{\text {max }}
$$


Where $F_{c e}$ is the muscle active contraction force, $\mathrm{A}(t)$ is the muscle activation level, $F_{l}(l)$ is the force-length curve, $F_{v}(v)$ is the force-velocity curve and $F_{\max }$ is the maximum isometric force. $F_{l}(l), F_{v}(v)$ and $F_{\max }$ were given by empirical formulas summarized by relevant scholars. The specific definition of each parameter can be found in the previous research [16]. To obtain driver's muscle activation level $A(t)$ during the emergency braking, volunteer emergency braking experiments were conducted in Laboratory of Applied Biomechanics of IFSTTAR. The volunteers were asked to sit on the simulator seat according to the driver's sitting posture, and keep a constant $4 \mathrm{~N}$ force on the acceleration pedal, simulating an average driving speed of $120 \mathrm{~km} / \mathrm{h}$. In order to simulate the emergency braking situation, after receiving the braking order, the volunteers slammed on the brakes for at least 3 seconds. Braking force, braking time and muscle EMG activities were recorded during the experiments. Details regarding the experimental procedure and experimental data processing have been reported in the previous studies [16, 22]. The average muscle active levels obtained after EMG signal data processing are shown in Table 1.

Table 1. Muscle active levels $\mathrm{A}(t)$

\begin{tabular}{ccc}
\hline Time & Muscle & $\mathrm{A}(t) \%$ \\
\hline & $\begin{array}{c}\text { musculi tibialis } \\
\text { anterior } \\
\text { gastrocnemius }\end{array}$ & $94 \pm 4$ \\
Start of braking & rectus femoris & $97 \pm 5$ \\
& $\begin{array}{c}\text { biceps flexor cruris } \\
\text { musculi tibialis } \\
\text { anterior }\end{array}$ & $87 \pm 4$ \\
Peak of braking & gastrocnemius & $46 \pm 5$ \\
force & rectus femoris & $60 \pm 5$ \\
& biceps flexor cruris & $26 \pm 5$ \\
\hline
\end{tabular}


Additionally, bone tissues were modelled with shell and solid elements. According to the anatomy of bone structure, different shell thicknesses and solid densities were used to simulate the epiphysis regions of long bones. The previous study found that such modelling method provides better prediction of strain distribution and bone fracture in the epiphysis regions than the uniform thickness approach [11]. The whole model consists of 22 muscle groups. Both passive property and active property of this model have been validated against recent relevant experiments. Model validation summary for occupant safety has been shown in the Appendix Table 1. More details supporting the present model have been reported in the previous study [16].

\subsection{Establishment of realistic impact environment}

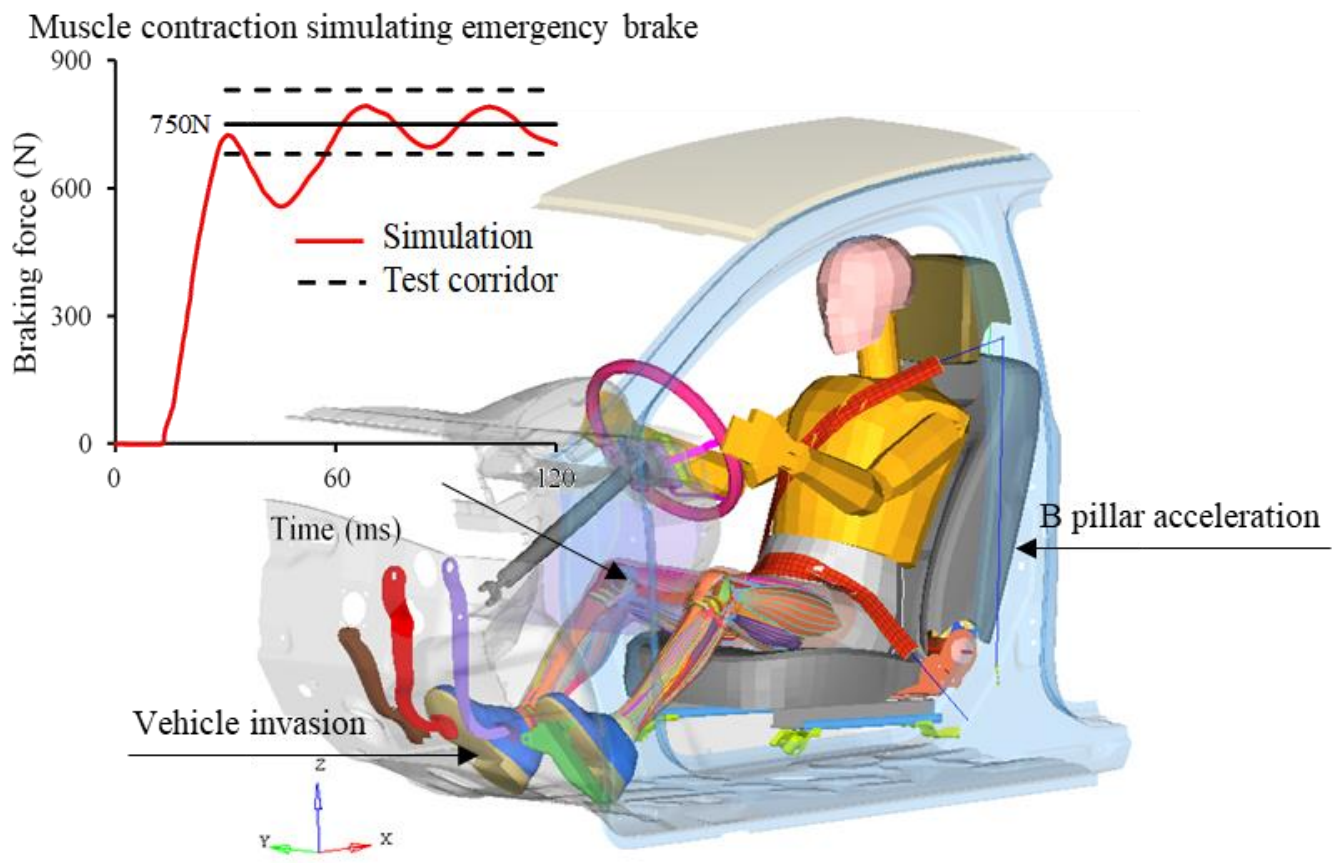

Figure 2. The frontal impact FE model with driver's emergency reaction for realistic impact environment simulation

In order to validate the validity of the lower limb-pelvis FE model, a realistic simulation of the emergency braking was conducted according to the volunteer experiments mentioned above. As shown in Fig. 2, the hybrid dummy model is made up of the validated lower limbpelvis model and the upper part of the 50th percentile Hybrid III dummy model. The lower 
limb-pelvis part of the dummy was removed. And then the new-developed pelvis FE model was constrained with the lumbar vertebrae part of the original dummy model. The driver's compartment is from a validated vehicle FE model produced by a Chinese Company. Since the emergency braking verification is a static experimental simulation, the restraint system was not considered. During the simulation, driver's lower limb muscles were activated to simulate driver's emergency braking action. The braking force was recorded in the simulation and then compared with that of the volunteer tests. As shown in Fig. 2, the braking force of the simulation is basically consistent with the data corridor of the volunteer tests.

Table 2 Simulation matrix of different frontal impact types and muscle status

\begin{tabular}{cccc}
\hline & $\begin{array}{c}100 \% \text { full } \\
\text { impact }\end{array}$ & $\begin{array}{c}40 \% \text { offset } \\
\text { impact }\end{array}$ & $\begin{array}{c}25 \% \text { offset } \\
\text { impact }\end{array}$ \\
\hline Inactive muscle & A0 & B0 & C0 \\
Active muscle & A1 & B1 & C1 \\
\hline
\end{tabular}

Then, a realistic frontal impact model including a detailed restraint system was eventually established based on the aforementioned driver's emergency reaction as shown in Fig. 2. Three typical frontal crash situations with different overlap rates were simulated including $100 \%$ full impact, $40 \%$ offset impact and $25 \%$ offset impact. As shown in Table 2, in order to investigate the effect of active muscles on lower limb injury, the simulations were classified into two groups with or without muscle activation. Each simulation consumed 24 CPUs and 8 hours. If the hybrid dummy and a full vehicle were both included to complete the whole collision process, the calculation process would be very long. Therefore, in this study, the acceleration curve of the B pillar and the invasion curve of the driver's compartment under different collision conditions were used as the input conditions of the simulations.

$100 \%$ frontal rigid wall collision $(50 \mathrm{~km} / \mathrm{h})$ and $40 \%$ offset collision $(64 \mathrm{~km} / \mathrm{h})$ based on China-New Car Assessment Program (C-NCAP) and 25\% small offset collision $(64 \mathrm{~km} / \mathrm{h})$ based on The US Insurance Institute for Highway Safety (IIHS) were simulated with a full 
vehicle model. Under different frontal collisions, the acceleration curves of B pillar (Fig. 3) and the invasion curves of the driver's compartment (Fig. 4 and Fig. 5) were recorded as input conditions of simulations in Table 2.

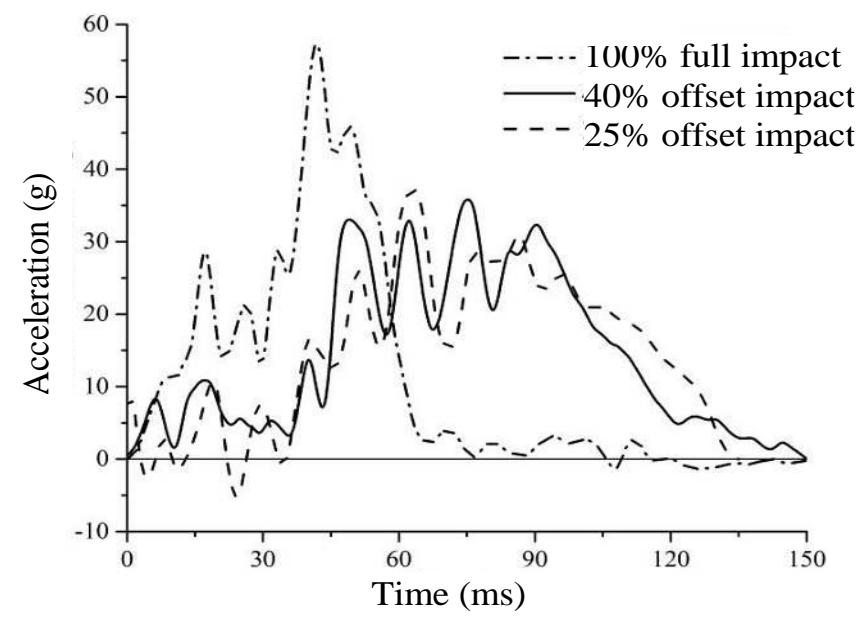

Figure 3. Acceleration curves of B pillar
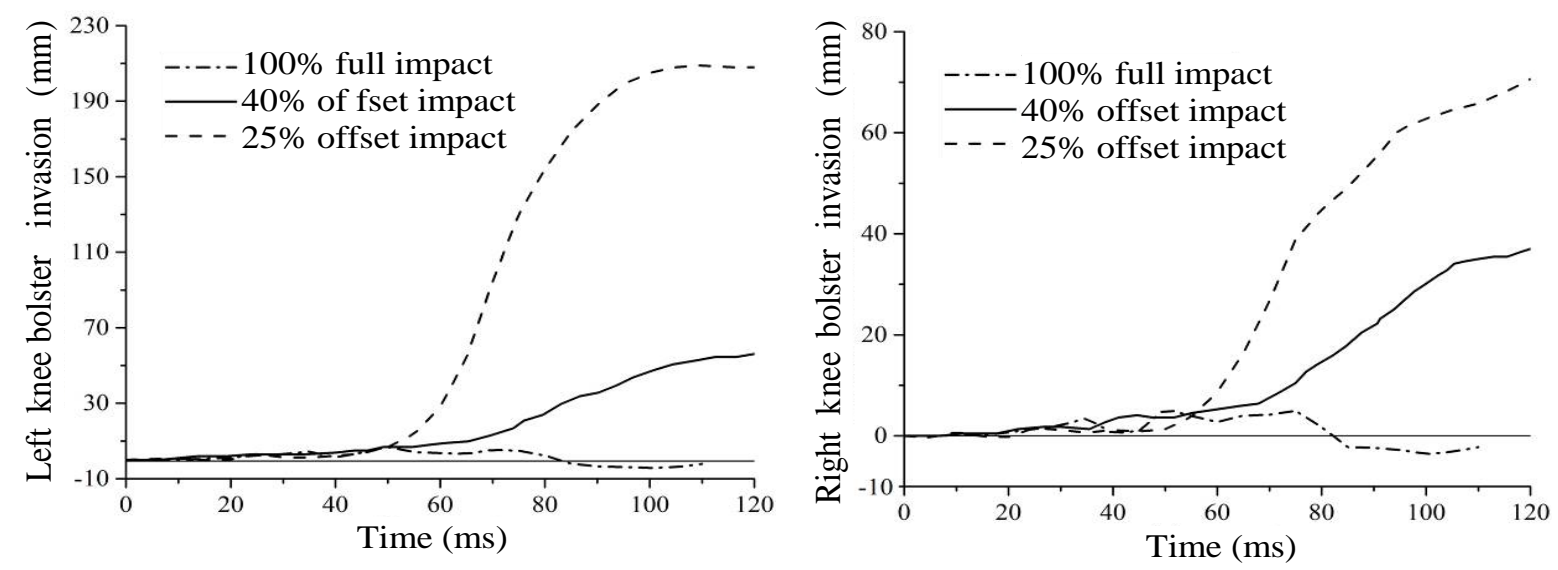

Figure 4. Invasion of left and right knee bolsters
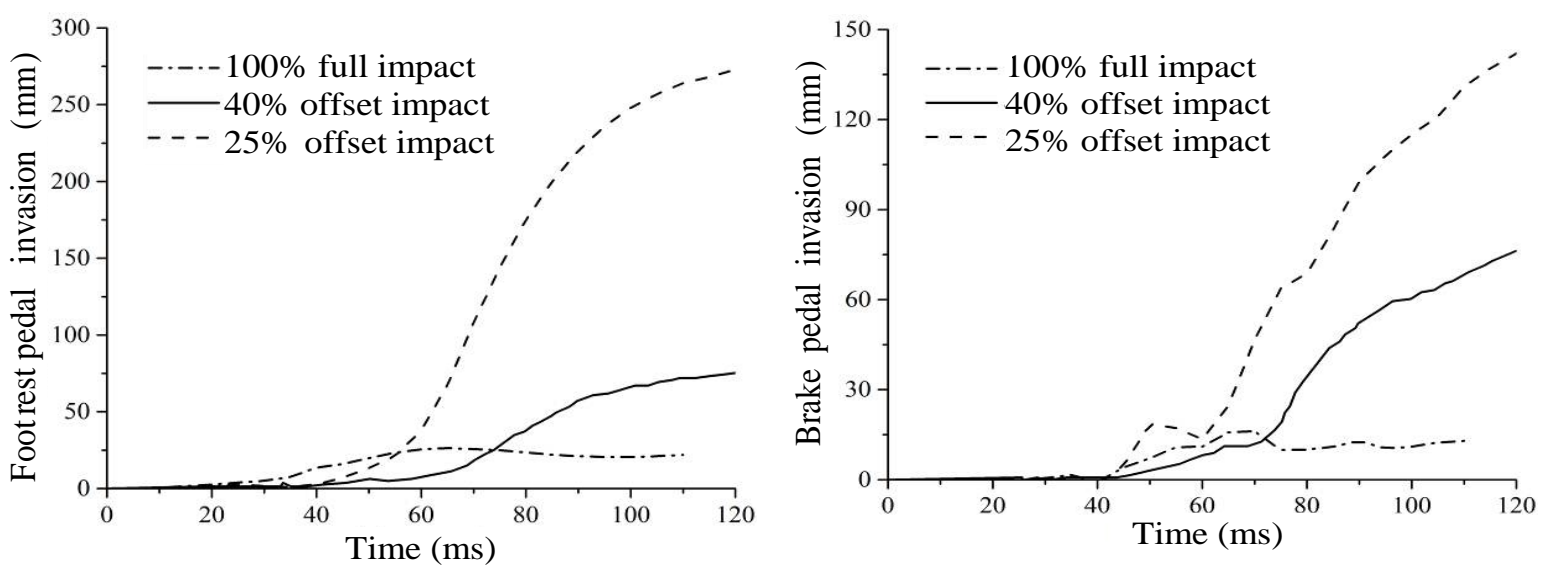

Figure 5. Invasion of footrest pedals and brake pedals 
Taking the $100 \%$ full impact simulation as an example, muscle active process and the input condition were set as shown in Fig. 6. When drivers are aware of the danger, most of them begin to slam on the brake after a brief reaction delay. Muscles are then activated, and the driver's lower extremity response will be affected by the muscle active contraction. According to Behr's experiments [20], after the driver starts braking, the vehicle will start decelerating at an average acceleration of $0.7 \mathrm{G}$. Each simulation began while the vehicle hit the barrier and lasted for $120 \mathrm{~ms}$. In this paper, we assume that muscle active contraction will be released after the femur force reaches its peak value.

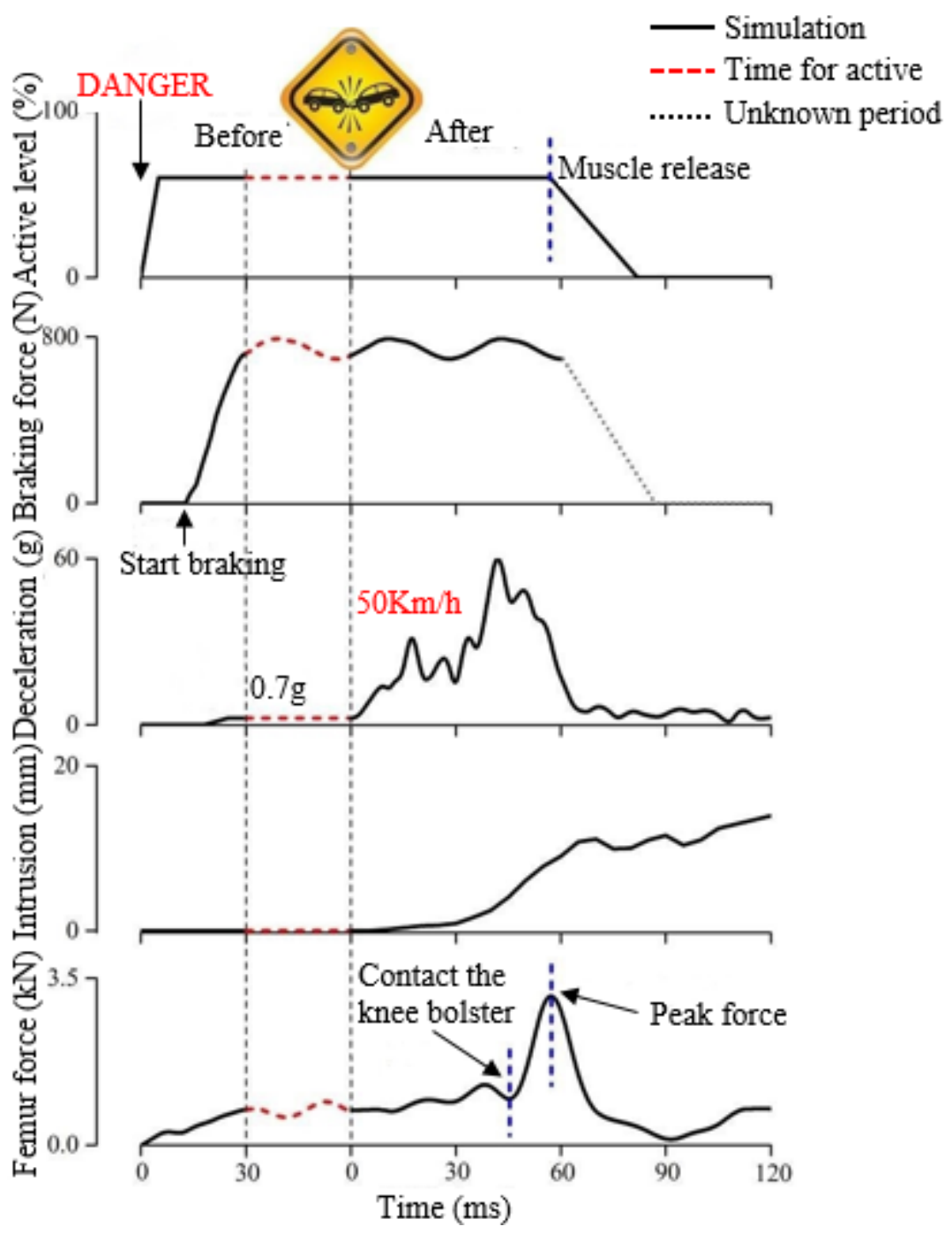

Figure 6. Frontal impact loading condition 
The evaluation indexes for lower limbs are tibia index, femoral axial force and resultant bending moment. Tibia Index (TI) is now widely used to evaluate occupant tibia injuries during the vehicle frontal impact. According to Nyquist et al. [23], a revised TI index with the thresholds of bending moment $M_{c}$ at $240 \mathrm{Nm}$ and axial force $F_{c}$ at $12 \mathrm{kN}$ was used to evaluate tibia injury risk. The formula is as follows.

$$
\mathrm{TI}=\frac{M}{M_{c}}+\frac{F}{F_{c}}
$$

\section{Results}

\subsection{KTH injury analysis}

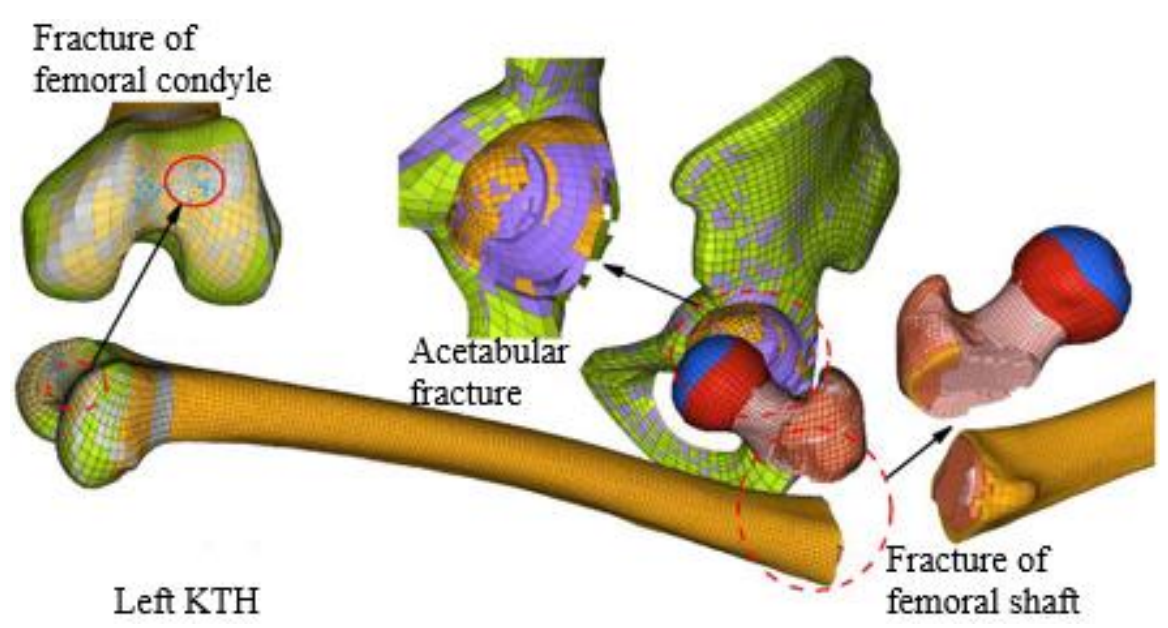

Figure 7. Typical injury occurrences of KTH in $25 \%$ overlap impact

There was no KTH injury found in $100 \%$ full impacts, and slight acetabulum failure were noted in $40 \%$ offset impacts. However, serious KTH injuries were found in $25 \%$ offset impacts both with and without muscle activation. As shown in Fig. 7, the femur fracture (modelled by element deletion) occurred around the lesser trochanter of the left thigh. Evident acetabulum fractures were also noted in the hip region. Besides, some element failures occurred in the contact area between the patella and the femoral condyles.

Axial forces of the femur are shown in Fig. 8. Compared with the other two kinds of impacts, the largest femoral axial forces occurred in $25 \%$ offset impacts. The corresponding peak forces of the left femur are $6.8 \mathrm{kN}$ in the inactive model and $5.97 \mathrm{kN}$ in the active model, 
respectively. The smallest axial femoral forces with values lower than $2.0 \mathrm{kN}$ occurred in $40 \%$ offset impacts. There was an evident axial femur force addition of about $1 \mathrm{kN}$ at the beginning of the simulation in cases with muscle activation. This phenomenon is obviously caused by the muscle active contraction which was modelled to simulate the emergency braking action.
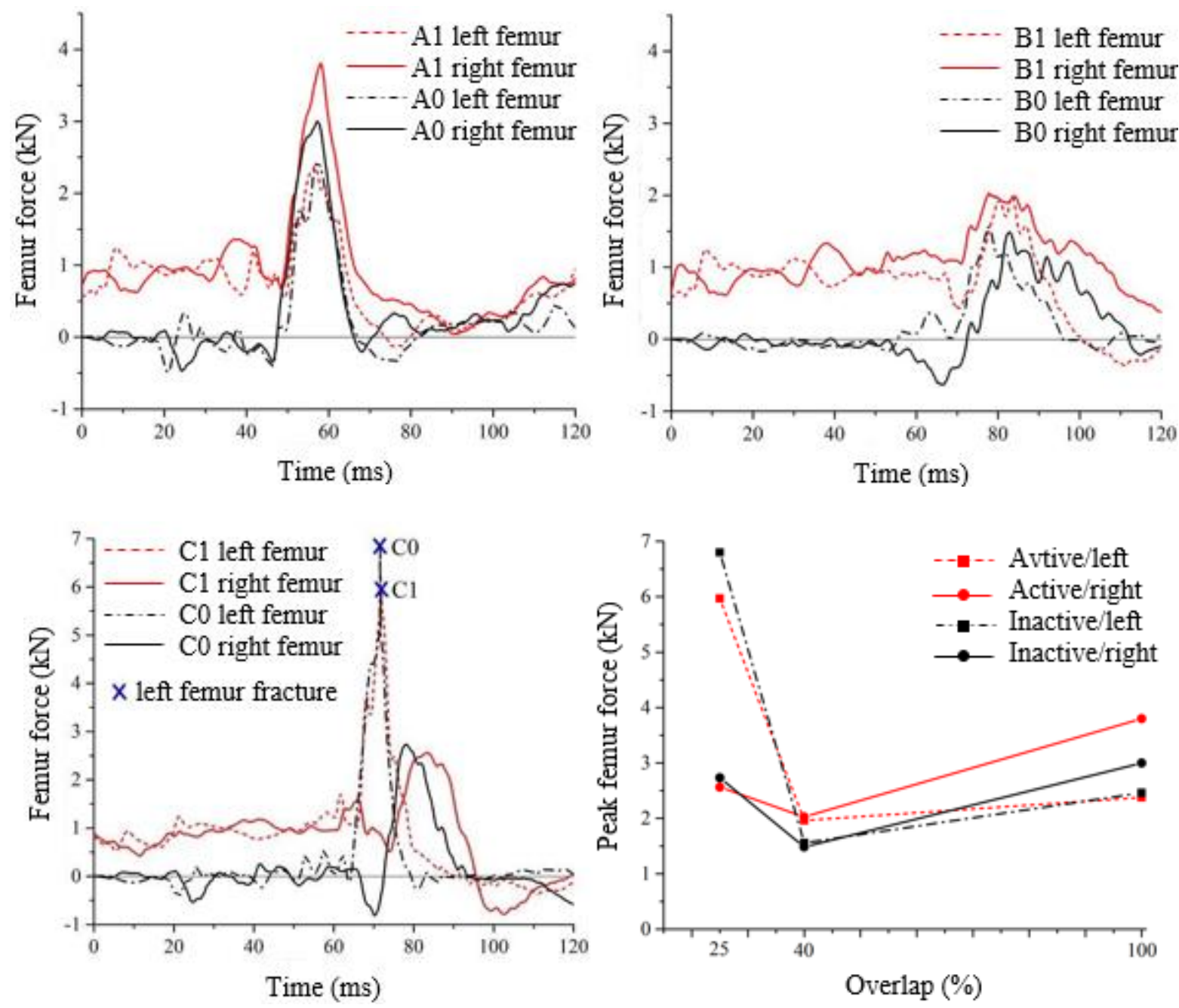

Figure 8. Femur axial forces in three impacts

In order to compare the femur resultant bending moment in different cases, sixteen cross sections were selected along the femur, referring to the previous study [24]. The bending moments of each section at the moment of the peak axial femur force were recorded in Fig. 9. Most femoral bending moments in active cases are larger than that in inactive cases at the same time and in the same position. The peak bending moments of active models are higher than that of inactive models by about $10-40 \mathrm{Nm}$. As for the $25 \%$ offset impacts where the femur fracture 
occurred, the bending moment of the left femur reached $175.3 \mathrm{Nm}$ in the active case, while in the inactive case the maximum value reached $163.6 \mathrm{Nm}$.
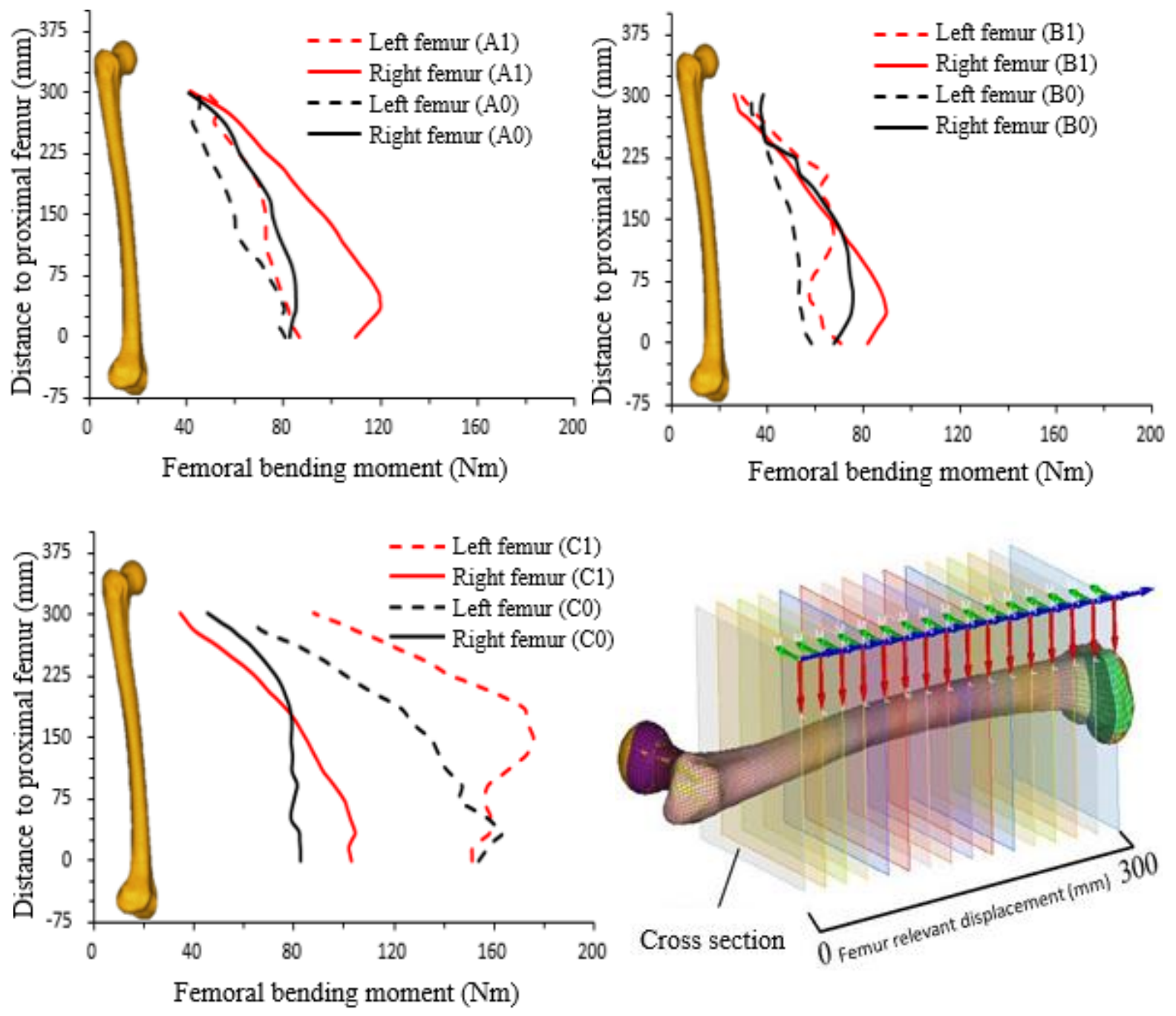

Figure 9. The max bending moments of cross section along the femur

\subsection{Tibia injury analysis}

As shown in Fig. 10, tibia stress distributions of 6 simulation groups were recorded when tibia maximum stress occurred during the impact. Obvious fractures were noted in the lower tibia of both legs in $25 \%$ overlap impact, which might be primarily caused by the great invasion of the brake pedal. The fibula fracture at its distal region was also found in $\mathrm{C} 0$ case, and both proximal and distal regions of the fibula were injured in $\mathrm{C} 1$ case. Besides, the upper right fibula fracture occurred in A1 case. Generally, groups with active muscles show higher stress compared with inactive groups as well as bone injury severity. 


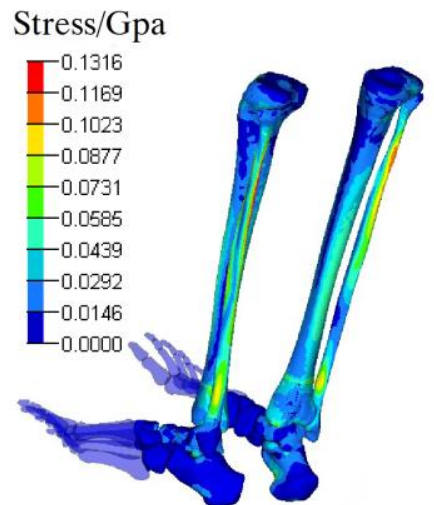

(a) A0 $54 \mathrm{~ms}$

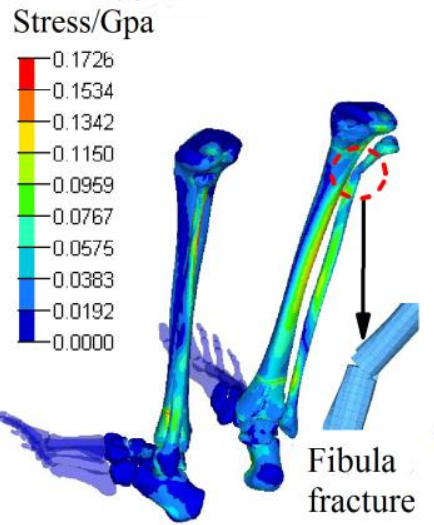

(d) A1 $54 \mathrm{~ms}$

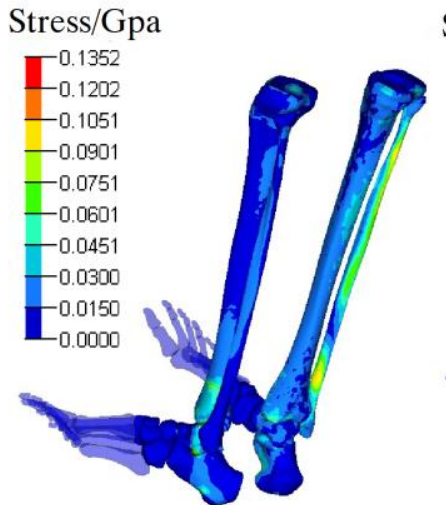

(b) B0 $82 \mathrm{~ms}$

Stress/Gpa

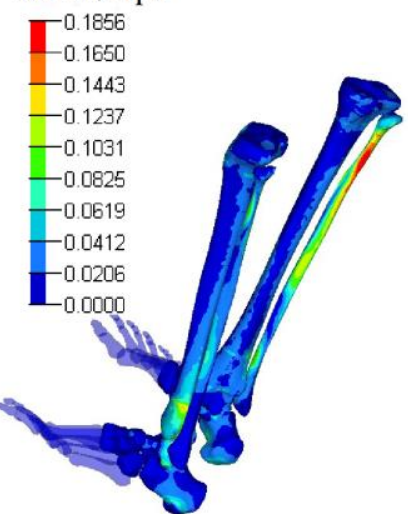

(e) B1 $82 \mathrm{~ms}$

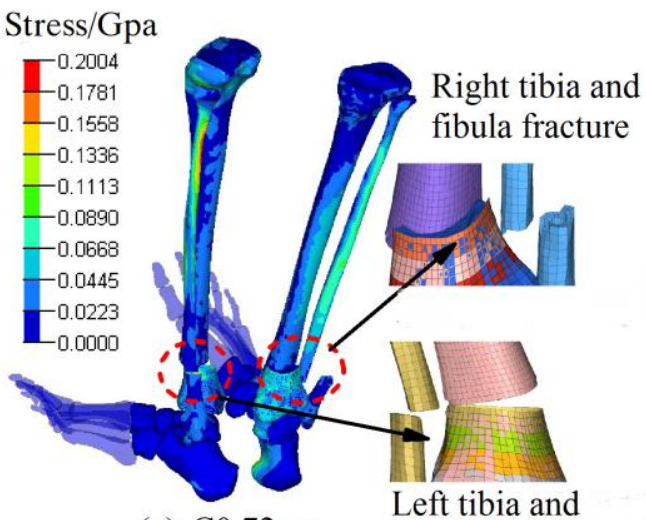

(c) $\mathrm{C} 072 \mathrm{~ms}$

Stress/Gpa

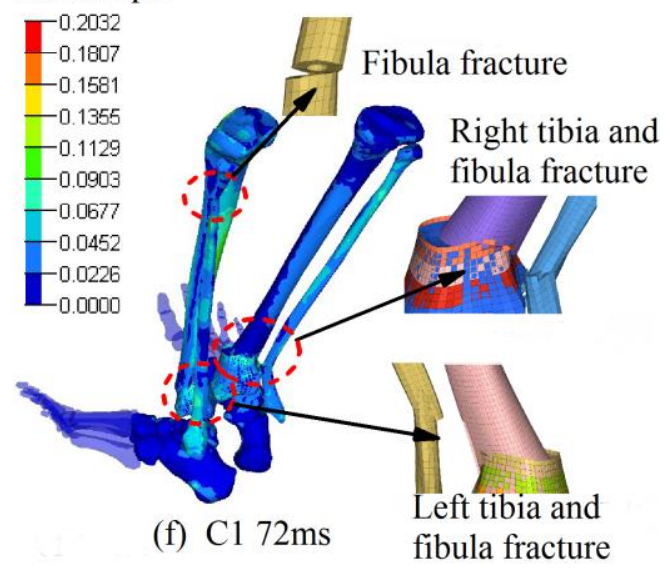

Figure 10. The peak stresses in the simulation of three impact types (GPa)

TI index values of the left and right tibia in all cases are shown in Fig. 11. Generally, the tibia index of active models is higher than that of inactive models. The TI peak value of $100 \%$ full impact occurred first, followed by $25 \%$ offset impact. The greatest TI was found in $25 \%$ offset impacts with obvious fractures of tibias and fibula. And the corresponding TI values are 0.55 (C0 left), 0.54 (C0 right), 0.82 (C1 left) and 0.59 ( $\mathrm{C} 1$ right). Other TI values without bone fracture are all lower than 0.5 . 

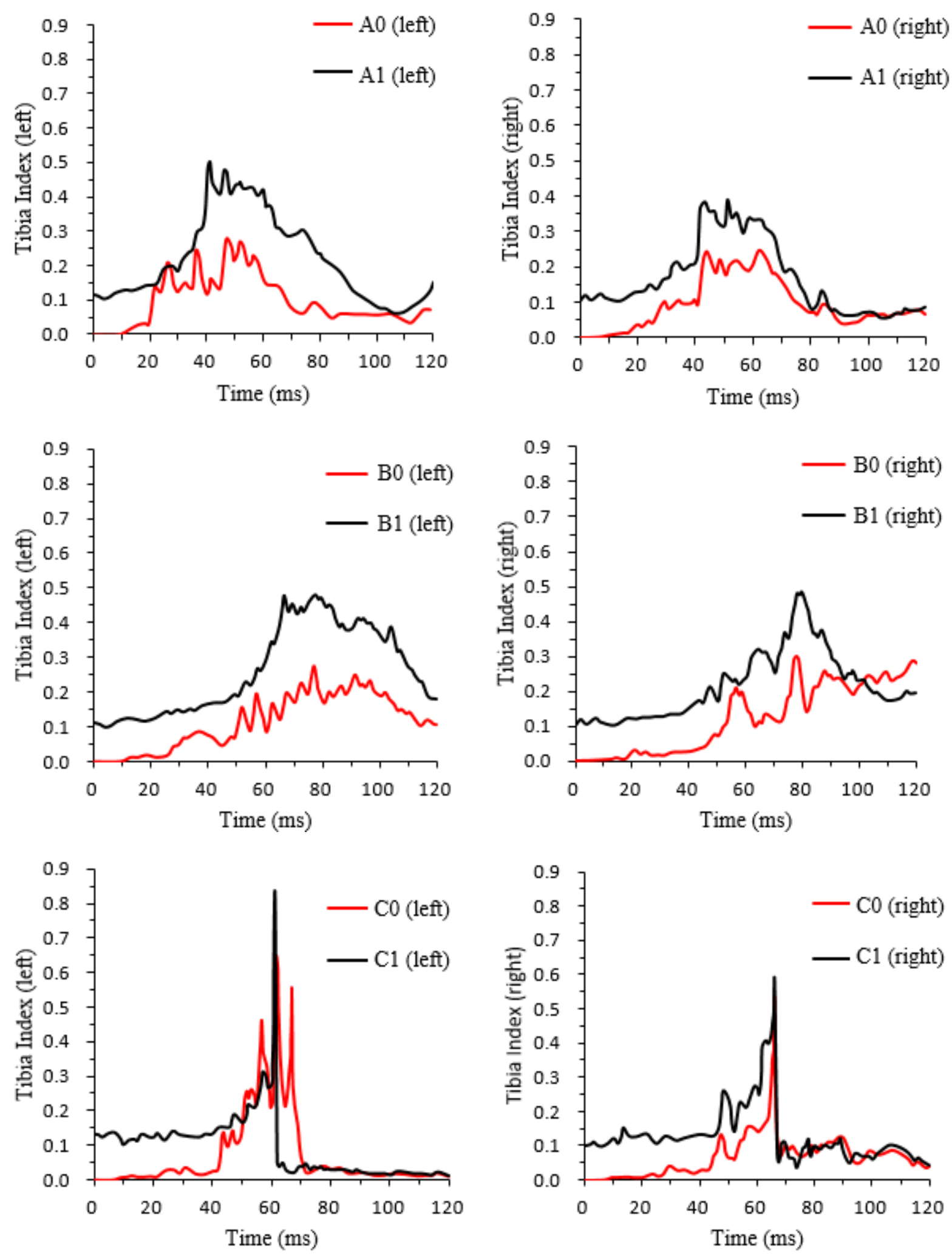

Figure 11. Tibia index in three impacts 


\section{Discussion}

Effect of active muscles on lower limb injuries was discussed in previous studies with simplified models and loading conditions. A model of the realistic impact environment was established with driver's muscle active contraction, the invasion of the driver's compartment and the response of the restraint system taken into consideration in this study. Driver's muscle active levels during the emergency braking were obtained by volunteer emergency braking experiments.

Considering the drivers' actual response and the repeatability of the driving simulation, there is an assumption in this study defined as follows: when the femur force reaches its peak value, the muscle contraction will be released. The influence of this assumption on the biomechanical responses of lower limbs is non-predicted. The present study used normalized EMG data from experiments for muscle activation level $A(t)$. EMG signals were related to muscle activation but still limited. And in the experiments, we can only measure part of muscles conveniently by surface EMG instrument. The present study only implements muscle activations for four dominant muscles related to braking behaviour. In the future, other methods for defining muscle activations can be studied. Our recent study indicates that combining musculoskeletal model method for pre-defined muscle activation can be a good choice for defining muscle activation in FE human body model [25]. In this case, more complicated human movement during driving can be simulated and studied. Additionally, the present study adopts one specific car model and three typical impact conditions. Different kinds of car models and more real impact conditions can be considered for further investigating the robustness of the present findings.

The simulation results show that the reactions of muscles when drivers realize the accident can significantly affect the kinematics and dynamics of lower limbs in the crash. As for KTH injuries, muscle contraction can lead to an obviously additional $1 \mathrm{kN}$ axial load on the femur at 
the moment of the impact. The femur resultant bending moment of active models is also higher than that of inactive models by about $10-40 \mathrm{Nm}$. Similar phenomenon can be found in the previous study [26]. It can be concluded that muscle activity may increase KTH injury risk by increasing both femur axial force and femur bending moment. Such mechanism was also discussed in the research of Chang et al. $[14,15]$.

Significantly, fracture of the driver's left femur occurred in both models in $25 \%$ offset impacts. The peaks of the femur axial force in models with and without active muscles are 6.8 $\mathrm{kN}$ and $5.97 \mathrm{kN}$, respectively. The values are both lower than $10 \mathrm{kN}$, which was defined by FMVSS 208 as a femur injury threshold and is now widely used. However, relatively high bending moment of the driver's left femur occurred in $25 \%$ offset impact, especially in the active case (175.3 Nm) (Fig. 10). This indicates that the combined action of axial force and bending moment of femur can be a main reason inducing femoral fracture. Thus, the bending moment should be involved in evaluating the femur injury during frontal crashes.

As for tibia injuries, at the initial stage of the impact, the tibial index of the model with muscle activation was about 0.1 higher than that of the model with non-activated muscles (Fig. 11). The active muscle force is considered as a main reason, which may increase both the axial force and the bending moment of tibia [26]. The TI values of the fractured tibias in all cases are far smaller than 1.0, which is widely used as a threshold to evaluate the tibia injury. The fracture occurs even when the TI value is around 0.6. And the tibia fractures primarily occurred around distal end of the tibia in this study. However, the currently widely used TI threshold values were generally based on the experimental results of the tibia mid-shaft. As the previous studies have noted that the tibia tolerance is significantly dependent on the injury area [27-29]. This phenomenon indicates that the TI index can evaluate combined loading but does not take into account the variation of the injury tolerance along the tibia shaft. 


\section{Conclusion}

This study aims to investigate the influence of active muscles on lower limb injuries with a new-developed lower limb FE model. The frontal impact loading sequence was set with an assumption defined in this paper, which aims to simulate a realistic impact environment. Besides, driver's emergency braking action, car body structure invasion and response of the restraint system were both taken into consideration. Three types of frontal impacts with different overlap rates were simulated and currently widely used lower limb injury indexes were implemented to evaluate the lower limb injury.

According to the simulation results, the non-ignorable effect of active muscles has been confirmed. The muscle contraction during the impact can significantly affect the kinematics and dynamics of lower limbs by inducing extra loads, which can explain the difference of the injury results between the real accidents and the cadaveric experiments in a way. Additionally, currently widely used lower limb injury criteria can be still lack of robustness. The injury indexes of femur and tibia were both lower than their corresponding thresholds when the injury occurred. Therefore, further research should focus on proposing comprehensive quantified indexes of lower limb injuries considering the active muscle effect, the combined action of different loads and the injury area.

\section{Acknowledgements}

This work is supported by National Natural Science Foundation of China (Grant No. 51621004, 51875187), Hunan Province Science and Technology Plan (Grant No. 2019JJ40021) and Foundation of Zhejiang Province Key Laboratory of Automobile Safety. 


\section{References}

1. Traffic Management Bureau of Ministry of public security. Annual report of the People's Republic of China on road traffic accident statistics (2000-2012). 2001-2013. Beijing.

2. Rudd RW. Updated analysis of lower extremity injury risk in frontal crashes in the United States. 21st ESV Conference 2009; 09-0556.

3. Melvin JW, Stalnaker RL, Alem NM, et al. Impact response and tolerance of the lower extremities. SAE Technical Paper 751159, 1975.

4. Powell WR, Ojala SJ, Advani SH, et al. Cadaver femur responses to longitudinal impacts. SAE Technical Paper 751160, 1975.

5. Viano DC, Stalnaker RL. Mechanisms of femoral fracture. Journal of biomechanics 1980; 113(8): 701-715.

6. Rupp JD. Biomechanics of hip injuries in frontal motor-vehicle crashes. Diss, 2006.

7. Kuppa S, Fessahaie O. An overview of knee-thigh-hip injuries in frontal crashes in the United States. National Highway Traffic Safety Administration 2003; ISSI 416.

8. Rupp JD, Reed MP, Van Ee CA, et al. The tolerance of the human hip to dynamic knee loading. SAE Technical Paper 2002-22-0011, 2002.

9. Laituri TR, Henry S, Sullivan K, et al. Derivation and theoretical assessment of a set of biomechanics-based, AIS2+ risk equations for the knee-thigh-hip complex. SAE Technical Paper 2006-22-0005, 2006.

10. Ivarsson BJ, Genovese D, Crandall JR, et al. The tolerance of the femoral shaft in combined axial compression and bending loading. SAE Technical Paper 2009-22-0010, 2009.

11. Untaroiu CD. A numerical investigation of mid-femoral injury tolerance in axial compression and bending loading. International journal of crashworthiness 2010; 15(1): 83-92. 
12. Untaroiu CD, Yue N, Shin J. A finite element model of the lower limb for simulating automotive impacts. Annals of biomedical engineering 2013; 41(3): 513-526.

13. Mo F, Duan S, Jiang X, et al. Investigation of occupant lower extremity injures under various overlap frontal crashes. International journal of automotive technology 2018; 19(2): $301-312$.

14. Chang CY, Rupp JD, Kikuchi N, et al. Development of a finite element model to study the effects of muscle forces on knee-thigh-hip injuries in frontal crashes. SAE Technical Paper 2008-22-0018, 2008.

15. Chang CY, Rupp JD, Reed MP, et al. Predicting the effects of muscle activation on knee, thigh, and hip injuries in frontal crashes using a finite-element model with muscle forces from subject testing and musculoskeletal modeling. SAE Technical Paper 2009-22-0011, 2009.

16. Mo F, Li F, Behr M, et al. A Lower Limb-Pelvis Finite Element Model with 3D Active Muscles. Annals of biomedical engineering 2018; 46(1): 86-96.

17. Ejima S, Zama Y, Ono K, et al. Prediction of pre-impact occupant kinematic behavior based on the muscle activity during frontal collision. 21st ESV Conference 2009; 09-0913.

18. Silvestri C, Ray MH. Development of a finite element model of the knee-thigh-hip of a 50th percentile male including ligaments and muscles. International Journal of crashworthiness 2009; 14(2): 215-229.

19. Schauer DA, Perfect S, Weiss J. Finite element modeling of the human anatomic pelvis and leg. NHTSA Draft Final Report 1997.

20. Behr M, Poumarat G, Serre T, et al. Posture and muscular behaviour in emergency braking: An experimental approach. Accident Analysis \& Prevention 2010; 42(3): 797-801. 
21. Iwamoto M, Nakahira Y, Kimpara H, et al. Development of a human body finite element model with multiple muscles and their controller for estimating occupant motions and impact responses in frontal crash situations. SAE Technical Paper 2012-22-0006, 2012.

22. Jammes Y, Behr M, Llari M, et al. Emergency braking is affected by the use of cruise control. Traffic injury prevention 2017; 18(6): 636-641.

23. Nyquist GW, Cheng R, El-Bohy AAR, et al. Tibia bending: strength and response. $S A E$ transactions $1985 ; 240-253$.

24. Mo F, Arnoux PJ, Avalle M, et al. Incidences of various passenger vehicle front-end designs on pedestrian lower limb injuries. International journal of crashworthiness 2015; 20(4): $337-347$.

25. Mo F, Li J, Dan M, Liu T, et al. Implementation of controlling strategy in a biomechanical lower limb model with active muscles for coupling multibody dynamics and finite element analysis. Journal of biomechanics 2019; 91:51-60.

26. Nie B, Sathyanarayan D, Ye X, et al. Active muscle response contributes to increased injury risk of lower extremity in occupant-knee airbag interaction. Traffic injury prevention 2018; 19(sup1): S76-S82.

27. Kerrigan JR, Bhalla KS, Madeley NJ, et al. Experiments for establishing pedestrian-impact lower limb injury criteria. SAE Technical Paper 2003-01-0895, 2003.

28. Mo F, Arnoux PJ, Jure JJ, et al. Injury tolerance of tibia for the car-pedestrian impact. Accident Analysis \& Prevention 2012; 46: 18-25.

29. Kerrigan JR, Drinkwater DC, Kam CY, et al. Tolerance of the human leg and thigh in dynamic latero-medial bending. International Journal of Crashworthiness 2004; 9(6): 607623.

30. Yamada H, Gaynor Evans F. Superior Designs. (Book Reviews: Strength of Biological Materials). Science 1971; 171: 57. 
31. Ehler E, Lösche H. Die menschliche tibia unter biegebelastung. Beitr. Orthop 1970; 17(5): 291-304.

32. Asang E. Experimental biomechanics of the human leg. A basis for interpreting typical skiing injury mechanisms. The Orthopedic clinics of North America 1976; 7(1): 63-73.

33. Keyak JH, Rossi SA, Jones KA, et al. Prediction of femoral fracture load using automated finite element modeling. Journal of biomechanics 1997; 31(2): 125-133.

34. Kitagawa Y, Ichikawa H, King AI, et al. A severe ankle and foot injury in frontal crashes and its mechanism. SAE transactions 1998; 2649-2660.

35. Guillemot H, Besnault B, Robin S, et al. Pelvic injuries in side impact collisions: a field accident analysis and dynamic tests on isolated pelvic bones. SAE transactions 1997 ; 36243633.

36. Hayashi S, Choi HY, Levine RS, et al. Experimental and analytical study of knee fracture mechanisms in a frontal knee impact. SAE Technical Paper 962423, 1996. 


\section{Appendix}

Table 1 The tolerance of the lower limb model

\begin{tabular}{|c|c|c|c|c|c|c|}
\hline & Test & Type & Direction & Peak & Tolerance & Reference \\
\hline \multirow{15}{*}{$\begin{array}{l}\text { Component } \\
\text { level } \\
\text { validation }\end{array}$} & $\begin{array}{l}\text { Femur 3-point } \\
\text { bending }\end{array}$ & \multirow{5}{*}{ Quasistatic } & \multirow{5}{*}{ A-P*: Mid } & $\begin{array}{c}3.82 \\
\mathrm{kN}\end{array}$ & $3.3 \pm 0.9 \mathrm{kN}$ & $\begin{array}{l}\text { Yamada, } \\
\text { et al. }\end{array}$ \\
\hline & Tibia 3-point & & & 3.338 & \multirow{2}{*}{$2.91 \pm 0.97 \mathrm{kN}$} & $1970[30]$ \\
\hline & bending & & & $\mathrm{kN}$ & & $\begin{array}{l}\text { Ehler, } \\
\text { et al. }\end{array}$ \\
\hline & Fibula 3-point & & & 0.449 & \multirow{2}{*}{$0.442 \mathrm{kN}$} & 1970 [31] \\
\hline & bending & & & $\mathrm{kN}$ & & $\begin{array}{c}\text { Asang. } \\
1976 \text { [32] }\end{array}$ \\
\hline & $\begin{array}{l}\text { Femoral head } \\
\text { Static pressure }\end{array}$ & Quasistatic & $\begin{array}{l}\text { Standing } \\
\text { posture }\end{array}$ & $\begin{array}{l}7.3 \\
\mathrm{kN}\end{array}$ & $8.4 \pm 3.0 \mathrm{kN}$ & $\begin{array}{c}\text { Keyak, } \\
\text { et al. } \\
1997 \text { [33] }\end{array}$ \\
\hline & \multirow{4}{*}{$\begin{array}{l}\text { Femur 3-point } \\
\text { bending }\end{array}$} & \multirow{9}{*}{ Dynamic } & \multirow{9}{*}{ L-M*: Mid } & 3.945 & \multirow{4}{*}{$\begin{array}{c}4.046 \pm 0.136 \mathrm{kN} \\
409.84 \mathrm{~N} \cdot \mathrm{m}\end{array}$} & \\
\hline & & & & $\mathrm{kN}$ & & \\
\hline & & & & 398.4 & & \\
\hline & & & & $\begin{array}{l}\mathrm{N} \cdot \mathrm{m} \\
3.15\end{array}$ & & $\begin{array}{l}\text { Kerrigan, } \\
\text { et al. }\end{array}$ \\
\hline & \multirow{3}{*}{$\begin{array}{l}\text { Tibia 3-point } \\
\text { bending }\end{array}$} & & & $\mathrm{kN}$ & \multirow{3}{*}{$\begin{array}{c}4.04 \pm 1.125 \mathrm{kN} \\
254 \pm 71 \mathrm{~N} \cdot \mathrm{m}\end{array}$} & 2003 [27] \\
\hline & & & & $\begin{array}{l}233.3 \\
\mathrm{~N} \cdot \mathrm{m}\end{array}$ & & Nyquist, \\
\hline & & & & 0.44 & & $1985[23]$ \\
\hline & Fibula 3-point & & & $\mathrm{kN}$ & $0.43 \mathrm{kN}$ & \\
\hline & bending & & & $\begin{array}{l}31.64 \\
\mathrm{~N} \cdot \mathrm{m}\end{array}$ & $21.7 \mathrm{~N} \cdot \mathrm{m}$ & \\
\hline \multirow{4}{*}{$\begin{array}{l}\text { System } \\
\text { level } \\
\text { validation }\end{array}$} & $\begin{array}{c}\text { Foot axial } \\
\text { impact }\end{array}$ & Dynamic & Axial & $\begin{array}{l}4.96 \\
\mathrm{kN}\end{array}$ & $5.25 \mathrm{kN}$ & $\begin{array}{c}\text { Kitagawa, } \\
\text { et al. } \\
1998[34]\end{array}$ \\
\hline & $\begin{array}{l}\text { Pelvis lateral } \\
\text { impact }\end{array}$ & Dynamic & L-M ${ }^{*}$ & $\begin{array}{l}3.55 \\
\mathrm{kN}\end{array}$ & $3.57 \pm 2.03 \mathrm{kN}$ & $\begin{array}{c}\text { Guillemot, } \\
\text { et al. } \\
1997 \text { [35] }\end{array}$ \\
\hline & $\begin{array}{l}\text { Knee bolster } \\
\text { impact }\end{array}$ & Dynamic & Axial & $\begin{array}{l}9.63 \\
\mathrm{kN}\end{array}$ & $10.1 \pm 0.3 \mathrm{kN}$ & $\begin{array}{l}\text { Hayashi, } \\
\text { et al. } \\
1996[36]\end{array}$ \\
\hline & $\begin{array}{l}\text { KTH knee } \\
\text { impact } \\
\text { KTH knee } \\
\text { impact }\end{array}$ & Dynamic & Axial & $\begin{array}{c}7.13 \\
\mathrm{kN} \\
5.81 \\
\mathrm{kN}\end{array}$ & $7.59 \pm 1.58 \mathrm{kN}$ & $\begin{array}{c}\text { Rupp, } \\
\text { et al. } \\
2002[8]\end{array}$ \\
\hline
\end{tabular}

*A-P: Anterior-Posterior, L-M: Lateral 